\title{
Tren Hypebeast Menurut Pandangan QS. An-Nisa (4) : 9 dan QS. Al-Anam (6) : 141
}

\author{
Arief Rahmadani, Soumana Sahla Ramadhan, Imamul Arifin \\ Politeknik Elektronika Negeri Surabaya \\ Politeknik Elektronika Negeri Surabaya \\ Politeknik Elektronika Negeri Surabaya \\ rahmadaniarif354@gmail.com
}

\begin{abstract}
Today the Hypebeast lifestyle is popular with various groups, especially teenagers. Hypebeast is a lifestyle where a person is obsessed with looking luxurious and willing to spend enough money to buy things that are booming (bype) to still look stylish and up to date. As the times evolve, Hypebeast Trends have become even broader, not only focusing on streetwear fashion but also discussing the lifestyle or trends of urban people. Hypebeast and how people apply this lifestyle become a problem if the trend is related to the content of the verses in the Koran and AlHadith. The correlation between the two is regarding the law of parents in educating their children which has been explained in the Qur'an An-Nisa verse 9 and the law of the person who wasted his wealth, which has been explained in surah Al-Anam verse 141. In Islam the law is has been arranged in such a way by Allah SWT. That makes Hypebeast trend activists, especially Muslims confused, whether this trend is allowed or not according to the view of the Koran and Al-Hadith. Based on the description and background above, the author explains the purpose of this article, which is to find out the relationship between hypebeast lifestyle trends with the Qur'an An-Nisa Verse 9 and Surat Al-Anam Verse 141.
\end{abstract}

Keywords: Hypebeast, Hedonism, Culture, Lifestyle

Abstrak. Dewasa ini gaya hidup bypebeast sedang digemari oleh berbagai kalangan khususnya para remaja. Hypebeast merupakan gaya hidup dimana seseorang terobsesi dengan berpenampilan bergaya mewah dan rela mengeluarkan uang cukup banyak untuk membeli barang-barang yang sedang booming (bype) untuk tetap terlihat stylish dan kekinian. Seiring berkembangnya zaman, Tren bypebeast pun menjadi lebih luas lagi tidak hanya fokus kepada fashion streetwear tetapi juga membahas gaya hidup atau tren orang-orang diperkotaan. Hypebeast dan bagaimana cara orang-orang dalam menerapkan gaya hidup ini menjadi sebuah permasalahan apabila tren tersebut dihubungkan dengan isi kandungan ayat-ayat dalam al-Quran dan Hadits. Korelasi antara keduanya yaitu mengenai hukum orang tua dalam mendidik anak-anaknya yang telah dijelaskan di dalam al-Qur'an Surat an-Nisa' ayat 9 dan hukum orang yang menyianyiakan hartanya, yang telah dijelaskan di dalam surah al-Anam ayat 141 . Di dalam agama Islam hukum tersebut telah diatur sedemikian rupa oleh Allah SWT. Hal itu membuat para penggiat tren hypebeast khususnya umat muslim kebingungan, apakah tren ini diperbolehkan atau tidak menurut pandangan al-Quran dan Hadits. Berdasarkan uraian dan latar belakang di atas maka penulis menjelaskan maksud 
tujuan dari artikel ini yaitu untuk mengetahui hubungan antara tren gaya hidup bypebeast dengan al-Qur'an surat an-Nisa' ayat 9 dan surat al-Anam ayat 141.

Kata Kunci: Hypebeast, Hedonisme, Budaya, Gaya Hidup

\section{PENDAHULUAN}

Gaya hidup merupakan pola atau cara hidup seseorang dimana berupa aktivitas seseorang, minat atau ketertarikan pada sesuatu, serta apa yang mereka akan pikirkan tentang diri mereka sendiri sehingga dapat membedakan statusnya dari orang lain maupun lingkungan melalui lambanglambang sosial yang mereka miliki. Menurut Kamus Besar Bahasa Indonesia, Gaya hidup merupakan pola tingkah laku setiap hari segolongan manusia dalam masyarakat. Sedangkan dari sisi ekonomi, gaya hidup merupakan perilaku setiap orang dalam menghabiskan uang mereka dan bagaimana mengalokasikan waktunya.

Dewasa ini gaya hidup bypebeast sedang digemari oleh berbagai kalangan khususnya para remaja. Hypebeast merupakan gaya hidup dimana seseorang terobsesi dengan berpenampilan bergaya mewah dan rela mengeluarkan uang cukup banyak untuk membeli barang-barang yang sedang booming (bype) untuk tetap terlihat stylish dan kekinian. Seiring berkembangnya zaman, Tren bypebeast pun menjadi lebih luas lagi tidak hanya fokus kepada fashion streetwear tetapi juga membahas gaya hidup atau tren orang-orang diperkotaan.

Hypebeast dan bagaimana cara orang-orang dalam menerapkan gaya hidup ini menjadi sebuah permasalahan apabila tren tersebut dihubungkan dengan isi kandungan ayat-ayat dalam al-qur'an dan hadits. Korelasi antara keduanya yaitu mengenai hukum orang tua dalam mendidik anak-anaknya yang telah dijelaskan di dalam al-qur'an surat an-Nisa' ayat 9 dan hukum orang yang menyianyiakan hartanya, yang telah dijelaskan di dalam surah alAn'am ayat 141. Di dalam agama Islam hukum tersebut telah diatur sedemikian rupa oleh Allah SWT. Hal itu membuat para penggiat tren bypebeast khususnya umat muslim kebingungan, apakah tren ini diperbolehkan 
atau tidak menurut pandangan al-qur'an dan hadist. Berdasarkan uraian dan latar belakang di atas maka penulis menjelaskan maksud tujuan dari artikel ini yaitu untuk mengetahui hubungan antara tren gaya hidup hypebeast dengan alqur'an surat an-Nisa' ayat 9 dan surat al-An'am ayat 141.

Di dalam artikel ini, penulis menggunakan metodologi peneletian jenis penelitian pustaka (library reseach) yaitu penelitian yang bersumber dari datadata kepustakaan atau penelitian dan ayat al-qur'an dan hadits yang berkaitan dengan masalah yang dihadapi yaitu tren hypebeast menurut pandangan alqur'an surat an-Nisa' ayat 9 dan surat al-An'am ayat 141. Adapun sifat dari penelitian ini adalah kualitatif, penelitian yang berasas pada kualitas dari datadata yang telah disusun dan diuraikan. Dengan demikian data-data yang berkaitan dengan rumusan masalah dapat diuraikan secara deskriptif kemudian dianalisis untuk diambil kesimpulannya.

Adapun teknik pengumpulan data penelitian yang kami gunakan dalam pembuatan karya tulis ilmiah ini yakni metode fusi-komparatif dari studi pustaka. Melalui metode ini kami dapat membandingkan beberapa kajian dari berbagai sumber, sehingga memperoleh inovasi yang validatif sebagai penggabungan beberapa analisis data. Metode ini bersifat abstraksi karena tanpa melalui tahap eksperimental, hanya melalui kajian yang kami dapatkan dari studi pustaka. Teknik Pengumpulan Data yang digunakan yaitu kajian dari berbagai sumber didapati berbagai macam analisis yang dapat kami bandingkan dan gabungkan sehingga menghasilkan kesatuan yang utuh berupa karya tulis ilmiah ini. Meskipun tanpa eksperimental langsung, karena didapati dari analisis serta kajian dari berbagai jurnal dan buku, maka dapat diketahui konsepsi ini mampu diterapkan pada saat percobaan langsung. Objek dan fokus penelitian ini adalah tren bypebeast atau Hedonisme serta alqur'an surat an-Nisa' ayat 9 dan surat al-An'am ayat 141. Adapun data yang diperoleh bersumber dari literature-literatur yang ada di perpustakaan, jurnal, skripsi, tafsir al-qur'an dan hadits serta beberapa artikel dengan sumber 
terpercaya di internet. Dalam menganalisis data yang diperoleh dari berbagai sumber, penulis menggunakan metode analisis deskriptif yaitu metode dengan menyusun data yang diperoleh, kemudian diinterpretasikan dan dianalisis, sehingga memberikan informasi bagi pemecah masalah yang dihadapi.

\section{HASIL DAN PEMBAHASAN}

\section{Pengertian Hypebeast}

Hypebeast adalah bahasa gaul yang telah menjadi tren di kalangan anak muda yang tergila-gila dengan tren mode pakaian jalanan akhir-akhir ini. Beberapa orang mungkin mengatakan kata ini untuk mengolok-olok anakanak yang terobsesi dengan produk-produk kelas atas sementara beberapa orang bangga diberi label istilah ini. Istilah ini pertama kali dipopulerkan pada tahun 2012 oleh rapper Trindad James dalam lagunya "All Gold Everytbing" (Beltran, 2018). Namun sejarahnya dapat ditelusuri kembali ke 2005 di mana "Majalah bypebeast yang terutama menggambarkan gaya hidup perkotaan, fashion, musik, dan gadget yang terutama membentuk gagasan banyak anak muda. Banyak orang menganggap arti kata ini dengan cara yang berbeda sesuai dengan perspektif mereka. Meskipun tidak ada definisi yang pasti, definisi yang diterima secara umum mungkin bahwa "itu adalah slang untuk seseorang yang" beast "(terobsesi) tentang merek-merek fasbion bype-up, dan dengan demikian akan melakukan segala cara untuk mencapai tipe itu" (Beltran, 2018).

Ada juga beberapa definisi tentang bypebeast yang dijelaskan dalam Urban Dictionary. Salah satu dari mereka menggambarkan hypebeast sebagai "anak kecil yang mengumpulkan pakaian, sepatu, dan aksesori untuk tujuan mengesankan orang lain. Meskipun orang tersebut mungkin tidak suka diberi label nama ini, mereka suka ke depan seolah-olah mereka membuat lebih dari orang lain. "Dilengkapi dengan kartu kredit mommy, hypebeast akan berusaha sekuat tenaga untuk memastikan dia memiliki setiap pasangan Nike yang dia 
lihat memakai JZ di 1068 Park." Seperti anak muda Inggris pasca perang, contoh yang diberikan oleh Mark Paterson dalam bukunya "Consumption of Everyday life" (2000), bypebeasts membentuk identitas mereka yang diekspresikan dari budaya mereka sendiri yang berbeda melalui tampilan kemakmuran dan hedonisme di depan umum. Banyak merek populer yang terobsesi dengan pemuda di masa yang berbeda termasuk Supreme, Ape, Offwhite, Yeezy, Billionaire Boys Club, Anti-Social Social Club, Vans, Dickies, Gucci, Prada atau Fendi. Banyak dari merek-merek tersebut adalah edisi terbatas yang tidak dapat diperoleh semua orang dan harganya jauh lebih tinggi daripada merek normal lainnya yang tersedia di mal dan toko-toko fashion kapan saja. Kebanyakan dari mereka juga penggemar berat sekolah baru Hip Hop, Mumble (sub-genre baru Hip hop) atau Electronic Dance.

\section{Ciri-Ciri Hypebeast}

Hypebeast adalah sebutan orang yang menggilai, mengikuti (terobsesi), dengan berpenampilan bergaya mewah dan rela mengeluarkan uang yang cukup banyak untuk membeli barang-barang yang sedang booming. Hypebeast sebenarnya merupakan sebuah majalah fashion yang berasal dari Amerika yang berisi tentang produk fashion yang sedang menjadi trend di dunia fashion saat ini. Yang menjadi bahasan paling utama pada majalah ini adalah tentang fashion streetwear serta barang-barang bype yang memiliki harga yang sangat tinggi. Namun pada perkembangannya dalam masyarakat, bypebeast menjadi sebuah penamaan untuk orang-orang yang memiliki tingkat urgensitas yang lebih tinggi terhadap fashion daripada masyarakat umum lainnya.

Eula Basa yang merupakan seorang bypebeast, telah mendeskripsikan identitas hypebeast dalam artikelnya "I Signs You are a Hypebeast" di sebuah situs web yang disebut Narcity. (Basa, 2016) menjelaskan tentang identitas mereka akan diekspresikan sesuai dengan apa sedang terjadi saat ini dalam budaya populer kaum muda. Daftar berikut menunjukkan sesuatu seperti apa yang 
biasanya dilakukan hypebeast. Namun, kita tidak boleh menggeneralisasi setiap penggemar pakaian jalanan yang memakai merek-merek itu karena favorit mereka daripada mereka yang memakainya untuk perhatian orang.

Hypebeast menganggap dirinya modis hanya jika ia memakai salah satu dan semua merek kelas atas secara bersamaan. Dia mungkin tidak akan pernah menoleh ke belakang apapun pakaian yang cocok untuknya atau tidak. Yang dia ingin tunjukkan adalah dia lebih unggul dari orang lain dengan mengenakan pakaian bermereknya.

Hypebeast berfokus pada pengeluaran semua peralatan terbaru daripada kebutuhan dasar. Itu berarti dia dapat menghabiskan semua uang saku untuk pakaian terbaru yang mahal. Ia bangga dengan koleksi sneaker atau snap yang luas. Tidak masalah jika ia menyukai sepatu atau snapback itu, ia biasanya membeli sepatu yang harganya mahal dan dikumpulkannya di lemari pakaian seperti ia memiliki selera yang sangat baik dalam mengonsumsi produk terbaik.

Bocah yang disebut kaya itu percaya bahwa sebuah merek akan hancur jika ia belum pernah mendengarnya. Meskipun dia mungkin menghabiskan banyak uang untuk merek-merek terkenal seperti Supreme, Fear of God, Yeezy, Nike atau Off White. Dia tidak akan membeli merek-merek pakaian yang tidak menjadi tren di kalangan komunitas yang disebut hypebeast. Dia membeli produk-produk kelas atas hanya karena nama-nama merek walaupun dia mungkin tidak secara pribadi tahu cerita-cerita latar belakang produk-produk tersebut, mengapa mereka bernilai banyak uang, yang telah dibuat sketsa oleh para desainer, atau perusahaan mana yang berkolaborasi di tahun yang mana atau dimana produk tersebut telah menjadi ikon.

Kadang-kadang, dia bahkan tidak tahu apakah dia suka atau tidak. Sebagai anak muda, ia jauh lebih dipengaruhi oleh pakaian selebritas daripada konsumen rata-rata. Karena pemaparan hiburan kontemporer melalui platform media, ia dapat mengambil beberapa artis terkenal yang populer di 
kalangan anak muda sebagai panutannya dan mungkin ingin meniru apa pun yang mereka lakukan dan juga termasuk cara mereka berpakaian. Sebagai contoh, ada banyak anak muda yang mengenakan "kaus bisbol agung" yang berwarna-warni di mana-mana tahun lalu setelah rilis video musik yang DJ Khaled, Quavo, Snoop Dog dan Justin Bieber telah berkolaborasi "Aku orangnya."

Hypebeast akan berkemah selama berjam-jam hanya untuk menangkap item edisi terbatas karena ia ingin memastikan bahwa ia mendapatkan item itu sebelum banyak orang lain memakai dan bype di jalanan. Dalam antrian untuk membeli barang seperti itu, ia biasanya memakai produk-produk bermerek yang telah menghabiskan banyak uang untuk membeli barangbarang tersebut agar ia dapat bersaing dengan teman-temannya atau orangorang bypebeast lain yang bersaing untuk mendapatkan barang itu dari di ruang pamer resmi.

Dia mengukur harga dirinya pada jumlah "Suka" dan reaksi di media sosial. Dengan mengenakan produk atau pakaian bermerek yang sedang tren dari kepala hingga ujung kaki, kadang-kadang mobil mewah di latar belakangnya, ia dapat meminta teman-teman dekatnya untuk mengambil foto di jalan-jalan atau tempat-tempat dengan latar belakang yang bagus seperti bar, mal atau pemandangan yang menginspirasi alam seperti bunga, jalan gunung yang berkelok-kelok, di atas bukit atau pantai, sunting dengan jelas dengan pengisi Instagram dan poskan foto-foto itu dengan menggunakan hashtag seperti \#ootd (pakaian hari ini) \#hypebeast \#hype \#litt dengan teks yang menginspirasi.

Keberhasilannya diukur bukan dalam prestasinya di dunia nyata tetapi dalam pujian di dunia virtualnya yang tidak bisa dia akses dengan tangannya. Akhirnya, bypebeast itu memastikan bahwa dia bersiap setiap kali dia keluar. Dia mungkin tidak mengaitkan pakaian mana (Beltran, 2018) yang harus 
mereka pakai dalam situasi apa, melainkan mengenakan setiap pakaian yang menurutnya membuatnya terlihat keren.

\section{Hypebeast Perspektif QS. an-Nisa' Ayat 9}

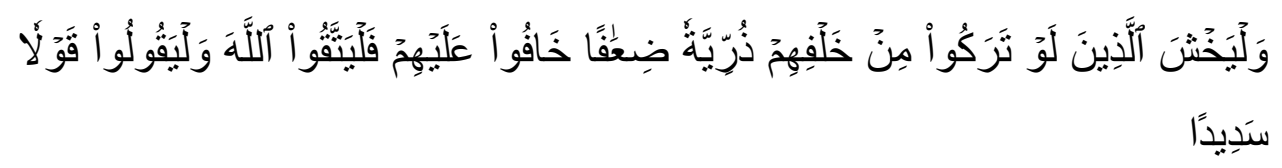

"Dan hendaklah takut kepada Allah orang-orang yang seandainya meninggalkan dibelakang mereka anak-anak yang lemah, yang mereka khawatir terhadap (kesejahteraan) mereka. Oleh sebab itu hendaklah mereka bertakwa kepada Allah dan hendaklah mereka mengucapkan perkataan yang benar."

Menurut tafsir Kementrian Agama, orang yang telah mendekati akhir hayatnya diperingatkan agar mereka memikirkan, janganlah meninggalkan anak-anak atau keluarga yang lemah terutama tentang kesejahteraan hidup mereka di kemudian hari. Untuk itu selalu bertakwa dan mendekatkan diri kepada Allah, selalu berkata lemah lembut, terutama kepada anak yatim yang menjadi tanggung jawab mereka.

Menurut tafsir Muyassar oleh tim Mujamma' Raja Fahd arahan Syaikh al-Allamah Dr. Shalih bin Muhammad Alu asy-Syaikh, orang-orang yang seandainya mereka mati dan meninggalkan anak-anak kecil lagi lemah sesudah mereka hendaknya takut dan khawatir mereka akan dizalimi dan disia-siakan. Maka hendaknya mereka bertakwa kepada Allah terhadap anakanak yatim dan lainnya yang menjadi tanggung jawab mereka.

Hal itu dengan menjaga harta mereka, mendidik mereka dengan baik, menepis gangguan dari mereka dan hendaknya mereka mengucapkan katakata yang sejalan dengan kebaikan dan keadilan. Korelasi antara tafsir ini dengan karya ilmiah ini yaitu dengan diperintahkannya menjaga harta serta larangan untuk meninggalkan anak dalam keadaan melarat.

Ahmad Hatta di dalam bukunya Tafsir Perkata menjelaskan, asbabun nuzul QS. an-Nisa ayat 9 berkaiatan dengan permintaan sahabat Sa'ad bin 
Abi Waqash. Pada waktu itu, Rasulullah sedang menjenguk Sa'ad yang sedang sakit keras.

Diceritakan dari Imam Mujahid, Sa'ad bin Abi Waqash berkata kepada Rasulullah SAW: Wahai Rasulullah, aku tidak memiliki ahli waris kecuali seorang anak perempuan. Aku boleh mengifakkan dua pertiga dari hartaku? Rasul pun menjawab, tidak boleh.

Lantas, Sa'ad bertanya lagi, separuh, ya Rasul ? Tidak, Jawab Rasul kagi. Jika sepertiga, ya Rasul? Kata Sa'ad. Kemudian nabi pun mengizikan, Ya, sepertiga juga sudah banyak. Lalu, Rasul bersabda, Lebih baik kamu meninggalkan ahli warismu dalam keadaan berkecukupan daripada miskin yang meminta-minta kepada manusia. (HR. Bukhari dan Muslim).

Dalam Tafsir al-Misbah, Prof. Dr. M. Quraish Shihab menjelaskan QS. an-Nisa ayat 9 merupakan pedoman bagi umat Islam agar memperhatikan kesejahteraan anak-anaknya. Ayat ini merupakan peringatakan bagi pemilik harta yang membagikan hartanya hingga anakanaknya terbengkalai.

Sehingga didalam membelanjakan harta, tidak semata-mata karena kesenangan diri sendiri, dalam kedudukan orang tua terdapat larangan untuk meninggalkan anak dalam keadaan lemah atau tidak mempunyai harta.

\section{Hypebeast Perspektif QS. al-An'am Ayat 141}

Hypebeast dan gaya hidup bermewah-mewahan merupakan sesuatu yang tidak bisa dipisahkan. Karena hypebeast merupakan sebuah bentuk dari hedonisme itu sendiri. Banyak orang yang melakukan gaya fashion dan gaya hidup bermewah-mewah hanya untuk mencitrakan diri mereka. Dengan kata lain, ada maksud dibalik tindakan bermewah-mewah yang dilakukan oleh seseorang dengan tujuan untuk mencapai sesuatu.

Walaupun tren bypebeast yang berujung hedonisme dipahami sekarang ini telah mengalami pergeseran adalah menikmati hidup dengan memanjakan diri, bersenang-senang dengan memuaskan keinginan dengan mengumpulkan 
harta sebanyak-banyaknya tampa memperdulikan orang lain. Sukses dan berhasil ketika seseorang dapat mencapai kenikmatan dan merasa senang, tolok ukur kebaikan menghindari kesusahan atau yang menyakitkan.

Hedonisme juga bisa muncul dalam kehidupan seorang muslim ketika tujuan hidupnya hanya memperturutkan hawa nafsunya dan tujuannya ingin meraih kesenangan sesaat di dunia ini saja. Hedonisme jelas bertentangan dengan ajaran Islam. Salah satunya yaitu tentang pengelolaan harta. Pengelolaan harta disini dapat diambil contoh yaitu menyia-nyiakan harta untuk membeli barang-barang mewah branded dan bype. Hal itu semua berhubungan dengan surah Al-Anam Ayat 141, yang berbunyi:

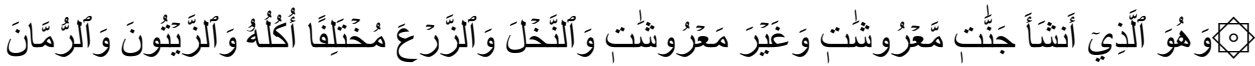

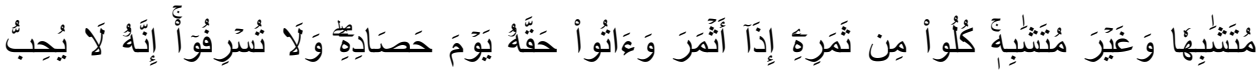

"Dan Dialah yang menjadikan kebun-kebun yang berjunjung dan yang tidak berjunjung, pohon korma, tanam-tanaman yang bermacam-macam buahnya, zaitun dan delima yang serupa (bentuk dan warnanya) dan tidak sama (rasanya). Makanlah dari buahnya (yang bermacam-macam itu) bila dia berbuah, dan tunaikanlah haknya di hari memetik hasilnya (dengan disedekahkan kepada fakir miskin); dan janganlah kamu berlebih-lebihan. Sesungguhnya Allah tidak menyukai orang yang berlebih-lebihan."

Dalam judul karya ilmiah kami hanya mengutip potongan QS. alAn'am ayat 141 pada bagian:

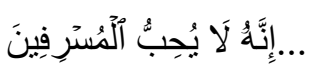

"...Sesungguhnya Allah tidak menyukai orang yang berlebih-lebihan." Ibnu Juraij berkata, dari Atha' (ia berkata): Itu larangan berlebihlebihan dalam segala hal.

Kemudian Ibnu jarir memilih perkataan Atha' itu: bahwa itu larangan berlebih-lebihan dalam segala sesuatu. (Tafsir Ibnu Katsir, dalam ayat 141 surat al-An'am). 
Dalam hadits shahih, Allah membenci otang yang menyia-nyiakan harta:

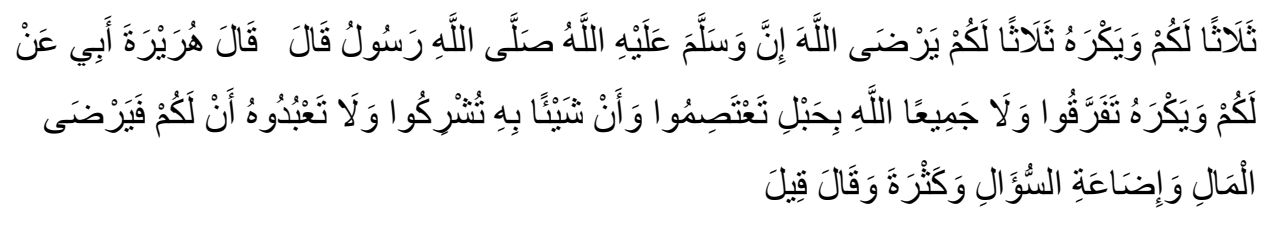

"Dari Abu Hurairah dia berkata, "Rasulullah shallallahu 'alaihi wasallam bersabda: "Sesungguhnya Allah menyukai bagimu tiga perkara dan membenci tiga perkara; Dia menyukai kalian bila kalian beribadah kepada-Nya dan tidak menyekutukan-Nya dengan sesuatu apapun, kalian berpegang teguh dengan agama-Nya dan tidak berpecah belah. Dan Allah membenci kalian dari mengatakan sesuatu yang tidak jelas sumbernya (qiila wa qaala), banyak bertanya dan menyia-nyiakan harta." (HR Muslim 3236)

Adapun (tentang dibencinya) menyia-nyiakan harta itu ada di hadits muttafaq 'alaih, karena hal itu tidak bermaslahat bagi agama maupun dunia. Hal itu dilarang, karena Allah Ta'ala menjadikan harta-harta itu sebagai kekuatan untuk kemaslahatan hamba-hamba. Sedang penghamburannya (tabdzir) itu menghilangkan maslahat-maslahat, baik dalam hak pelaku yang menyia-nyiakan harta ataupun dalam hak orang lain. (Ihkamul Ahkam Syarah 'Umdatul Ahkam juz 2 halaman 20/Maktabah Syamilah). Menurut Dr Mushthafa Dib al-Bagha, dosen Hadits di Fakultas Syari'ah Damsik, menyianyiakan harta yaitu dengan membelanjakannya dalam maksiat atau berlebihan (menghamburkannya) dalam hal yang mubah (dibolehkan). (Komentar/ ta'liq di hadits Bukhari).

Menyambung pengertian menyia-nyiakan harta bahwa ada tiga hal perbuatan manusia yang dibenci oleh Allah SWT dan harus dijauhi agar terhindar dari dosa. Dari Abu Hurairah radhiyallahu 'anhu, ia berkata bahwa Rasulullah shallallahu 'alaihi wa sallam bersabda,

"Sesungguhnya Allah meridhai tiga hal dan membenci tiga hal bagi kalian. Dia meridhai kalian untuk menyembah-Nya, dan tidak menyekutukan sesuatu pun dengan-Nya, serta berpegang teguhlah 
kalian dengan tali Allah dan tidak berpecah belah. Dia pun membenci tiga hal bagi kalian, menceritakan sesuatu yang tidak jelas sumbernya, banyak bertanya, dan membuang-buang harta." (HR. Muslim no. 1715)

Didalam hadist diatas juga dijelaskan bahwa Allah membenci manusia yang menyia-nyiakan atau membuang-buang hartanya.

\section{Cara Menyikapi Tren Hypebeast}

Kuatkan Iman dan Pengendalian diri

Dorongan untuk menikmati sesuatu muncul dari hawa nafsu yang sulit merasa puas. Cenderung tidak mengenal aturan halal atau haram. Yang dapat mengendalikan hanyalah kekuatan iman seseorang. Bersyukur, Harus memperbanyak syukur. Bersyukur kepada Allah berarti menyadari betapa banyak nikmat yang Allah berikan kepada kita. Walau pun dalam keterbatasan materi kita tetap harus bersyukur karena ada kenikmatan lain berupa nonmateri yang begitu banyak dicurahkan Allah kepada kita hamba-Nya, terutama nikmat iman.

Beramal dan Bersedekah

Untuk yang satu ini mungkin terdengar sedikit klise. Beramal dan bersedekah bisa menghindari Anda dari perilaku bedon. Anda akan berpikir bahwa masih banyak orang yang tidak seberuntung Anda dan membutuhkan uluran tangan Anda. Hal tersebut akan membuat Anda berpikir dua kali ketika ingin menghambur-hamburkan uang.

Hidup Sederhana

Dengan memulai hidup sederhana, maka seorang anak akan memulai hidup dengan mengutamakan kebutuhan bukan keinginan atau tuntutan nafsu semata. Dengan menanamkan gaya hidup yang sederhana bisa terhindar dari pemborosan atau keserakahan. 
Qanaah

Qana'ah adalah sikap rela menerima dan selalu merasa cukup dengan apa yang sudah maksimal dilakukan, serta menerima dengan lapang dada hasil yang diperoleh. Qana'ah adalah bagian dari rasa syukur atas nikmat yang diberikan Allah dan merasa puas dengan apa yang didapatkan.

\section{PENUTUP}

Dalam kajian dan pencarian referensi mengenai tren Hypebeast menurut pandangan Surah An-Nisa Ayat 9 dan Surah Al-Anam Ayat 141 dapat disimpulkan bahwa tren Hypebeast yang diiringi dengan sifat hedonism sangat bertentangan dengan apa yang di perintah dan dilarangan oleh Allah SWT .Sebenarnya tren Hypebeast tidak akan menjadi masalah, selama sesuai dengan perintah dan larangan dari Allah SWT. Dikarenakan di zaman sekarang ini konteks Hypebeast telah disamakan dengan perliaku hedonisme.Dalam agama Islam sudah diajarkan atau digariskan kepada setiap pemeluknya untuk menjadi manusia-manusia yang taat dan konsisten memegang teguh agamanya, pada saat kapan, dimanapun dan berhubungan dengan siapapun. Sayangnya, tidak sedikit di kalangan pemeluk agama IslAm ini yang terjerumus dalam berbagai bentuk penyimpangan. Mereka membenarkan jenis-jenis perilaku yang bertentangan dengan doktrin Islam, dan bahkan apa yang diperbuatnya ini bukan hanya merugikan dirinya, melainkan juga merugikan orang lain dan citra agama yang dipeluknya (Islam). Kerugian atau dampak demikian kadang diabaikannya.

\section{REFERENSI}

(n.d.). Retrieved from Tafsir Surat Al-Anama Ayat 141-142: http://www.ibnukatsironline.com/2015/05/tafsir-surat-al-anamayat-141.html

An Nisa 4-9. (n.d.). Retrieved from Risalah Muslim: https://risalahmuslim.id/quran/an-nisaa/4-9/ 
Basa, E. (2016). 9 Signs you're definitely a Hypebeast,. Retrieved from Naracity: https://www.narcity.com/ca/on/toronto/lifestyle/9-signs-youredefinitely-a-hypebeast

Beltran, S. (2018, Maret 14). What is a 'bypebeast and where do you find them. Retrieved from Esquire Middle East: https://www.esquireme.com/content/26947-what-is-a-hypebeastand-where-do-we-fin

Hikmah, M. (2019, Agustus 19). Tiga Hal yang Allah Benci, Harus Dibindari! Retrieved from Dakta.com: http://www.dakta.com/news/20076/tiga-hal-yang-allah-benci-harusdihindari

Ismail, M. (2019). Hedonisme dan Pola Hidup Islam. Jurnal Ilmiah Islam Resources Volume 16 Nomor 2 FAI-UMI Makassar, 193-204.

Muchsin, M. B. (2019). PERSPEKTIF ETIKA ISLAM TERHADAP HEDONISME PEMELUK AGAMA. PENDIDIKAN MULTIKULTURAL VOLUME 3 NOMOR 2, 207-218.

Quran Surat An-Nisa Ayat 9. (n.d.). Retrieved from Tafsirweb: https://tafsirweb.com/1541-quran-surat-an-nisa-ayat-9.html

Ranti Tri Anggraini, \& Fauzan Heru Santhoso. (2017). Hubungan antara Gaya Hidup Hedonis dengan. GADJAH MADA JOURNAL OF PSYCHOLOGY, VOLUME 3, NO. 3, 131-140.

Widjaja, A., Aiat, S., \& L.D.Leksmono, D. (2019, September 14th \& 15th). The Phenomenon of "Hypebeast" among Young People in Indonesia. 15th International Conference onLanguage, Literature, Culture and Education, pp. 011-011. 